\title{
INHIBITION OF THE RESPIRATORY-LINKED MEMBRANE POTENTIAL IN E. COLI MEMBRANE VESICLES BY OCTAPEPTIN
}

\author{
Paul E. Swanson and Daniel R. Storm \\ Department of Pharmacology, University of Washington, \\ Seattle, Washington 98195, U.S.A. \\ (Received for publication February 9, 1979)
}

\begin{abstract}
Octapeptin is a peptide antibiotic which affects bacterial membrane structure and selective membrane permeability for protons and potassium. The influence of octapeptin on the formation of a membrane potential generated across bacterial vesicles was monitored using the $\mathrm{Rb}^{+}$-valinomycin transport system. Octapeptin inhibited the respiratory-linked generation of membrane potentials formed in the presence of succinate or Asc/PMS. In addition, the antibiotic inhibited $\left[{ }^{3} \mathrm{H}\right]$-leucine transport driven either by succinate or Asc/PMS. These studies support the proposal that the antimicrobial activity of octapeptin is due to inhibition of the formation of a membrane potential generated in the presence of appropriate respiratory substrates.
\end{abstract}

The octapeptins are a closely related class of peptide antibiotics ${ }^{11}$ which exhibit a broad range of antimicrobial activity against Gram-positive and Gram-negative bacteria ${ }^{2)}$. The octapeptins are structurally related to the polymyxins and are characterized by a cyclic octapeptide containing a $\mathrm{C}: 10$ or $\mathrm{C}: 11 \beta$-hydroxy fatty acid attached to the peptide through an amide bond ${ }^{3,4,5)}$.

A number of biochemical processes in bacteria are affected by octapeptins but mechanistic studies have strongly implicated the bacterial membrane as the primary site of action ${ }^{6}$. Previous studies have indicated that the effects of octapeptin on bacterial metabolism are similar to those of uncouplers of oxidative phosphorylation ${ }^{7)}$. The antibiotic stimulated bacterial respiration at concentrations corresponding to minimum inhibitory concentrations. It also enhanced the membrane proton permeability and lowered the adenosine 5 -triphosphate pool size. It was proposed that octapeptins disrupt the selective ion permeability of the cytoplasmic membrane, thereby relaxing the membrane potential. In the present study, this hypothesis was directly tested by examining the influence of octapeptin on the membrane potential in E. coli membrane vesicles. It is demonstrated that octapeptin inhibits both formation of the membrane potential generated in the presence of respiratory substrates and respiratory coupled leucine transport.

\section{Materials and Methods}

\section{Materials}

Octapeptin (EM49).4HCl was obtained from the Squibb Institute for Medical Research. Valinomycin, CCCP, sodium ascorbate, and sodium succinate were obtained from Sigma. PMS was obtained from Aldrich, sodium azide from Eastman, L-leucine from ICN, and RbCl from Apache Chemicals. $\quad\left[{ }^{3} \mathrm{H}_{3}\right]-\mathrm{L}$-Leucine $(116 \mathrm{Ci} / \mathrm{mmole})$ and $\left[{ }^{8} \mathrm{Rb}^{+}\right] \mathrm{Cl}^{-}(364 \mathrm{mCi} / \mathrm{mmole})$ were obtained from New England Nuclear. $25 \mathrm{~mm}$ Cellulose acetate filters $(0.45 \mu)$ were purchased from Curtis Matheson Scientific, Inc.

* Abbreviations: Asc/PMS, phenazine methosulfate reduced by ascorbate; $\mathrm{CCCP}$, carbonyl cyanide $m$ chlorophenylhydrazone; MIC, minimum inhibitory concentration. 
Methods

Growth of Bacteria and Preparation of Vesicles

Escherichia coli strain ML-308-225 was grown on Minimal Medium $\mathrm{A}^{8)}$ containing $1 \%$ sodium succinate as a carbon source and a trace of $\mathrm{FeSO}_{4} \cdot 7 \mathrm{H}_{2} \mathrm{O}(0.00005 \%)$. Membrane vesicles were prepared as described ${ }^{9)}$, and $1 \mathrm{ml}$ aliquots were frozen and stored in liquid $\mathrm{N}_{2}$ at $4.5 \mathrm{mg}$ protein $/ \mathrm{ml}$ in $100 \mathrm{~mm}$ potassium phosphate at $\mathrm{pH} 6.6$.

Transport Assays

In all cases, frozen vesicles were thawed rapidly at $46{ }^{\circ} \mathrm{C}$. For $\left[{ }^{3} \mathrm{H}_{3}\right]$-leu transport assays, the vesicles were diluted to $1 \mathrm{mg}$ protein $/ \mathrm{ml}$ in $100 \mathrm{~mm}$ potassium phosphate, $\mathrm{pH} 6.6$, incubated at $25^{\circ} \mathrm{C}$ for 20 minutes and stored on ice until assayed. All transport assays were done in buffers containing no $\mathrm{Mg}^{2+}$ since it inhibits the antimicrobial activity of octapeptin ${ }^{11)}$. $\mathrm{Mg}^{2+}$ is not required for the coupling of respiration to either leu transport or valinomycin facilitated $\mathrm{Rb}^{+}$transport. For ${ }^{86} \mathrm{Rb}^{+}$uptake, the vesicles were treated as previously described ${ }^{10)}$ using $100 \mathrm{~mm}$ sodium phosphate, $\mathrm{pH}$ 6.6, throughout. Final suspensions were in the same buffer at $1 \mathrm{mg}$ protein/ml. Valinomycin was added ( 2 nmoles/mg protein) and the vesicles were then stored on ice until assayed.

All assays were performed at $25^{\circ} \mathrm{C}$ in $13 \times 100 \mathrm{~mm}$ test tubes using an apparatus previously described $^{10)}$ with $\mathrm{O}_{2}$ used to aerate the samples. All radiolabelled substrates, electron donors, inhibitors, and antibiotics were added $(0.5 \sim 1.0 \mu \mathrm{l})$ to $100 \mu \mathrm{l}$ aliquots of the vesicles at the concentrations indicated using Hamilton syringes. Following removal from the ice, the vesicles were incubated for 3 minutes prior to addition of the electron donor and the radiolabelled substrate. Unless indicated otherwise, all antibiotics or inhibitors were added 1 minute prior to the addition of electron donors.

Uptakє: of either $\left[{ }^{3} \mathrm{H}_{3}\right]$-leu or ${ }^{86} \mathrm{Rb}^{+}$was determined by rapid filtration on cellulose triacetate filters $(0.45 \mu)$ using $100 \mathrm{~mm} \mathrm{LiCl}$ throughout to dilute and wash the samples. With the exception of the release studies, all time points represent the time between addition of the radiolabelled substrate and dilution with $100 \mathrm{~mm} \mathrm{LiCl}$. Filters were thoroughly dried and allowed to completely dissolve in scintillation fluid before counting. Each data point was corrected for nonspecific binding of radioactively labelled ligands using controls which were treated identically in the absence of an electron donor. Calculations of intravesicular concentrations of either $\left[{ }^{3} \mathrm{H}_{3}\right]-$ leu or ${ }^{86} \mathrm{Rb}^{+}$assumed a value of $2.2 \mu \mathrm{l}$ internal volume/mg protein ${ }^{12)}$. Membrane potentials determined from ${ }^{86} \mathrm{Rb}^{+} \mathrm{uptake}$ experiments were calculated using the NERNST equation; $\Delta \psi=58.8 \log \left[{ }^{86} \mathrm{Rb}^{+}\right]_{\mathrm{IN}} /\left[{ }^{36} \mathrm{Rb} \mathrm{b}^{+}\right]_{\text {out }}$. It was assumed that the ratio of $\left[{ }^{86} \mathrm{Rb}^{+}\right]_{\mathrm{IN}} /\left[{ }^{86} \mathrm{Rb}^{+}\right]_{\text {OUT }}$ was one in the absence of an electron donor $\left(\Delta \psi^{\prime}=0\right)$.

Protein was determined by the method of LowRY ${ }^{13)}$.

\section{Results}

Influence of Octapeptin on Formation of the Membrane Potential

A number of radiolabelled ions have been used to monitor formation of the electrical potential generated by respiration in bacterial membrane vesicles $\left.{ }^{14}{ }^{18}\right)$. These include the lipophilic cations dimethyl dibenzyl ammonium and triphenyl methyl phosphonium as well as ${ }^{86} \mathrm{Rb}^{+}$(with valinomycin). Initial experiments indicated that octapeptin interacted quite strongly with the lipophilic cations, but not with ${ }^{86} \mathrm{Rb}^{+}$and valinomycin. Therefore, the ${ }^{86} \mathrm{Rb}^{+}$-valinomycin transport system ${ }^{18)}$ was used to measure the formation of a membrane potential in the presence or absence of octapeptin.

The influence of octapeptin on the formation of the membrane potential by $E$. coli vesicles is presented in Fig. 1. Membrane potentials were established using either succinate (Fig. 1A) or Asc/ PMS (Fig. 1B) as electron donors. In the absence of octapeptin, a membrane potential was rapidly generated using either respiratory substrate, although the rate and extent of membrane potential formation was lower with succinate compared to Asc/PMS. The maximum membrane potentials formed in the presence of succinate and Asc/PMS were 59 and $66 \mathrm{mV}$ respectively. Formation of 
Fig. 1. Succinate dependent (A) and Asc/PMS dependent (B) ${ }^{86} \mathrm{Rb}^{+}$uptake by E. coli membrane vesicles in the presence of octapeptins concentrations of zero, $10 \mu \mathrm{M}, 50 \mu \mathrm{M}$ and $100 \mu \mathrm{M}$.

Membrane vesicles were prepared as described in Methods, at a final concentration of $1 \mathrm{mg}$ membrane protein $/ \mathrm{ml}$.

Sodium succinate, sodium ascorbate, PMS and ${ }^{86} \mathrm{RbCl}$ were at concentrations of $20 \mathrm{~mm}, 20 \mathrm{~mm}$, $100 \mu \mathrm{M}$ and $2 \mathrm{~mm}$, respectively.
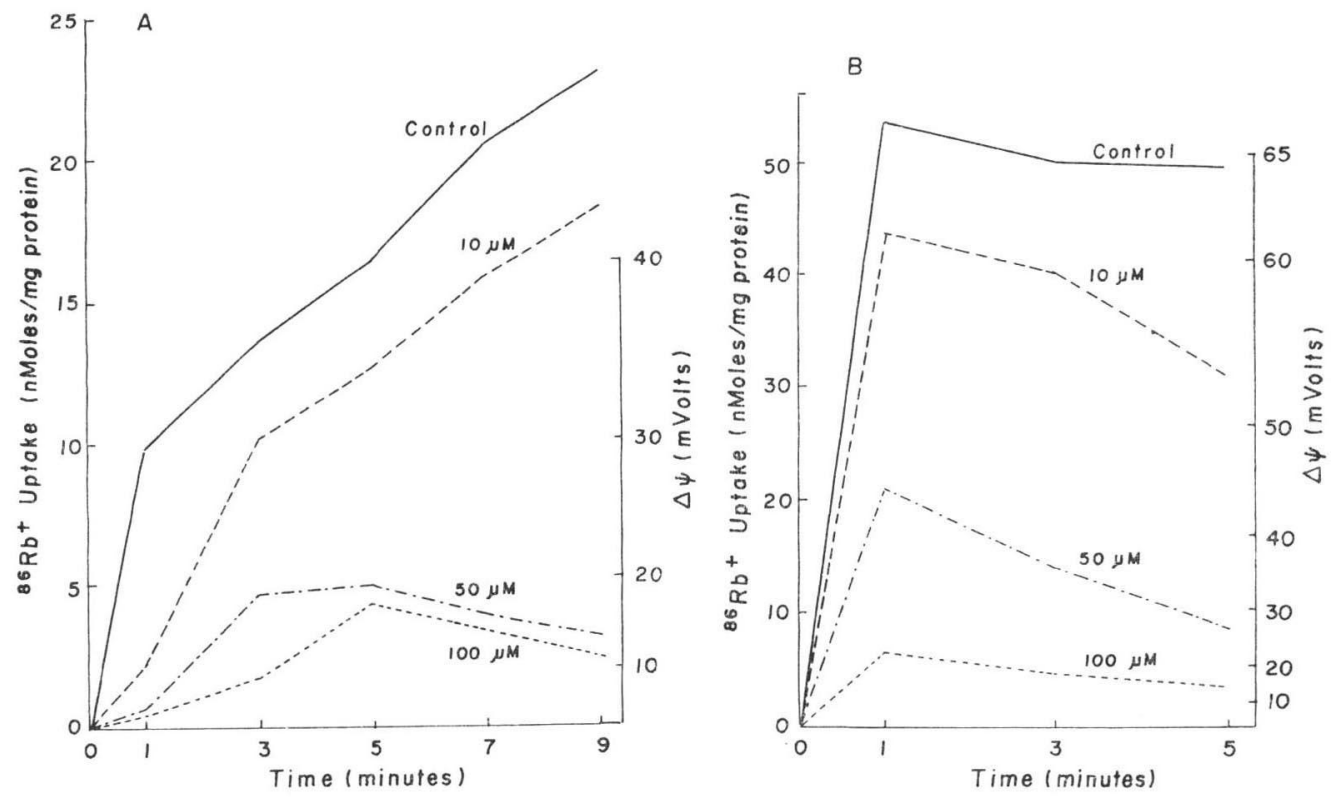

the membrane potential generated in the presence of either succinate or Asc/PMS was markedly inhibited by octapeptin (Fig. 1). For example, the maximum Asc/PMS generated membrane potentials were $66,62,44$ and $25 \mathrm{mV}$ in the presence of $0,10,50$ and $100 \mu \mathrm{M}$ octapeptin, respectively. Complete inhibition of membrane potential formation was achieved at $200 \mu \mathrm{M}$ octapeptin (not shown).

The concentrations of octapeptin required to affect the membrane potential may seem relatively high since the minimum inhibitory concentration of the antibiotic for this E. coli strain is approximately two micromolar. However, relatively high concentrations of membrane vesicles were required for monitoring uptake of ${ }^{86} \mathrm{Rb}^{+}$compared to concentrations of bacteria used in the determination of minimum inhibitory concentrations. These two measurements are most appropriately compared using the ratio of total octapeptin to membrane lipid required to affect bacterial growth or ${ }^{86} \mathrm{Rb}^{+}$uptake. Formation of the membrane potential was markedly inhibited by $50 \mu \mathrm{M}$ octapeptin which corresponds to a molar ratio of total octapeptin to membrane lipid phosphate of 0.50 . The corresponding ratio at the minimum inhibitory concentration was 0.60 moles total octapeptin per mole of lipid phosphate. Thus, bacterial growth and membrane potential formation were inhibited at comparable ratios of antibiotic to membrane phospholipid. Binding studies using $\left[{ }^{3} \mathrm{H}\right]$-octapeptin and whole bacteria or isolated membranes indicated that there was approximately one mole of antibiotic bound per 50 moles of membrane phospholipid at minimum inhibitory concentrations of the peptide.

The effects of octapeptin on ${ }^{86} \mathrm{Rb}^{+}$uptake were compared to CCCP since CCCP is a proton conductor which effectively collapses the electrical potential across bacterial membrane systems ${ }^{17}$. The influence of CCCP on membrane potentials generated in the presence of succinate or Asc/PMS 
Fig. 2. Succinate dependent (A) and Asc/PMS dependent (B) ${ }^{86} \mathrm{Rb}^{+}$uptake by E. coli membrane vesicles in the presence of CCCP.

Experimental conditions are identical to those indicated in Fig. 1.
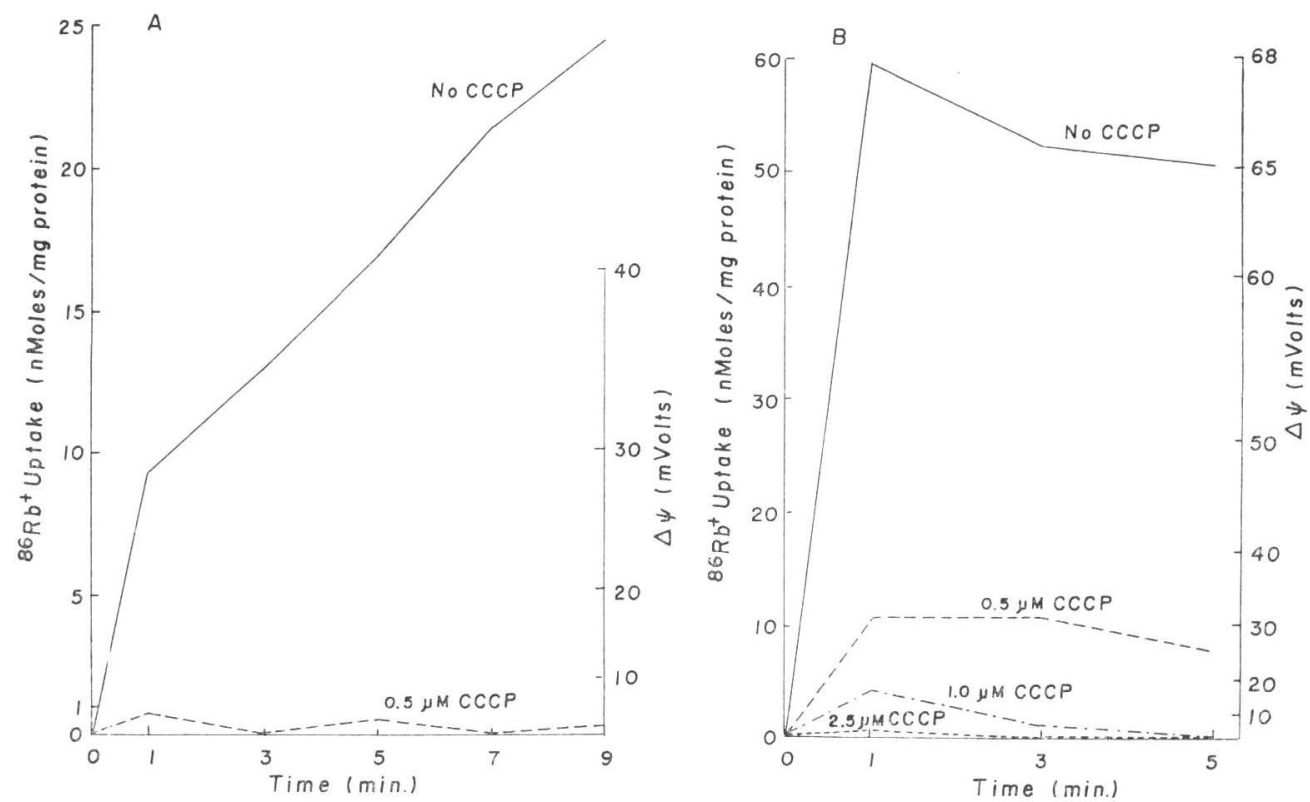

was qualitctively similar to octapeptin (Fig. 2). CCCP inhibited both the rate and extent of membrane potential formation. However, CCCP was clearly more effective than octapeptin since comparable effects required $20 \sim 50$-times higher octapeptin concentrations.

\section{Influence of Octapeptin on Leucine Transport}

The data discussed above illustrated that octapeptin inhibited the formation of the membrane potential in the presence of appropriate electron donors. Therefore, one would expect the antibiotic to inhibit active transport of metabolites which are driven by the membrane potential ${ }^{14,17,19,20)}$. Fig. 3 illustrates that $\mathrm{KABACK}$ vesicles accumulated $\left[{ }^{3} \mathrm{H}\right]$-leucine against a concentration gradient in the presence of succinate (Fig. 3A) or Asc/PMS (Fig. 3B). Succinate driven accumulation of $\left[{ }^{3} \mathrm{H}\right]$ leucine was less effective than Asc/PMS.

Octapeptin inhibited leucine transport driven by either respiratory substrate (Fig. 3). Inhibition of leucine transport by octapeptin varied as a function of the peptide concentration. For example, Asc/PMS driven leucine transport was inhibited $25 \%, 66 \%$ and $100 \%$ at octapeptin concentrations of 10,50 and $100 \mu \mathrm{M}$ (Fig. 3B). By comparison, membrane potential formation was inhibited $38 \%$, $82 \%$ and $94 \%$ at octapeptin concentrations of 10,50 and $100 \mu \mathrm{M}$ (Fig. 1B). A similar correlation was observed between octapeptin inhibition of membrane potential formation and leucine transport when succinate served as the electron donor (Fig. 1A and Fig. 3A). These observations strongly suggest that octapeptin inhibition of leucine transport is due to direct effects of the peptide on the membrane potential.

Inhibition of leucine transport by octapeptin could conceivably reflect either of two actions of the peptide; collapse of the electrochemical membrane gradient or enhancement of leucine membrane 
permeability. The latter possibility was examined by preloading KABACK vesicles with $\left[{ }^{3} \mathrm{H}\right]$-leucine for $10 \mathrm{~min}$ utes in the presence of succinate and following the kinetics for release of leucine in the absence or presence of azide, azide and CCCP or azide and octapeptin (Fig. 4). It was not technically feasible to remove succinate and extravesicular $\left[{ }^{3} \mathrm{H}\right]-\mathrm{leu}-$ cine prior to examining back leakage of accumulated $\left[{ }^{3} \mathrm{H}\right]$-leucine. In the absence of any effectors, $\left[{ }^{3} \mathrm{H}\right]$-leucine levels continue to be maintained at about 0.20 nmoles/mg membrane protein. In the presence of azide, the net rate of leucine efflux was enhanced considerably indicating that continued electron transport was required to maintain leucine in the vesicles against a concentration gradient. Presumably, there is normally a high basal rate of leucine leakage counteracting leucine uptake in the presence of an electron donor. A combination of azide and $\mathrm{CCCP}$, which blocks formation of the membrane potential and also relaxes the accumulated membrane potential, enhanced the net rate of leucine efflux even further. A similar rate of net leucine efflux was observed in the presence of azide and octapeptin. Thus, octapeptin did not appear to increase leucine permeability beyond that observed when generation of the membrane potential was blocked and the membrane potential was relaxed simultaneously.

\section{Inhibition of Leucine Transport by CCCP}

The data discussed so far have shown that octapeptin is effective in inhibiting both the gene-
Fig. 4. Release of $\left[{ }^{3} \mathrm{H}\right]$-leucine from E. coli membrane vesicles preloaded for 10 minutes in the presence of succinate as described in Fig. 3, prior to treatment with effectors.

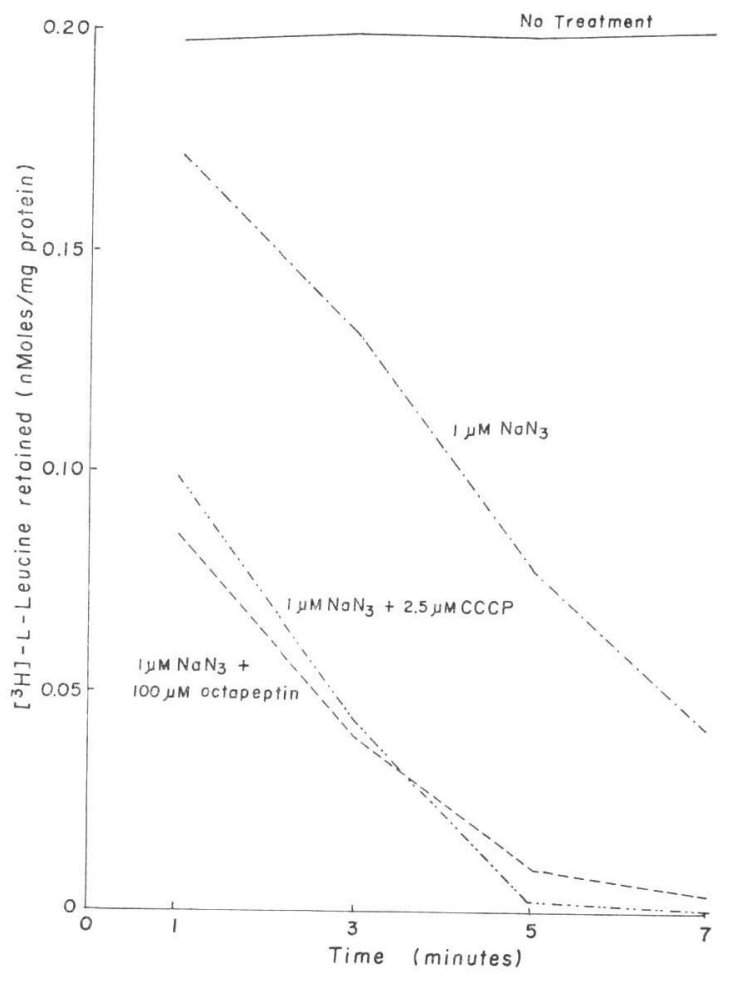


ration of a membrane potential and respiratory coupled transport of leucine. With Asc/ PMS as a respiratory substrate, CCCP was effective in inhibiting formation of the membrane potential (Fig. 2) and is almost equally effective with respect to $\left[{ }^{3} \mathrm{H}\right]$-leucine transport (Fig. 5). In both cases, $2.5 \mu \mathrm{M}$ CCCP was just sufficient for $100 \%$ inhibition, arguing for a direct relationship between the membrane potential and active transport of leucine.

\section{Discussion}

It has been previously demonstrated that octapeptin binds to bacterial membranes ${ }^{6,11}$, causes observable changes in membrane structure $^{11)}$ and increases membrane permeability with respect to protons and $\mathrm{K}^{+7}$. These membrane permeability changes were restricted to small ions. Octapeptin treatment of bacterial cells did not result in release of larger molecular weight molecules such as nucleotides, amino acids or proteins ${ }^{11}$. On the basis of these observations, it was proposed that the primary action of octapeptin is to increase the membrane permeability for small ions and relax the membrane potential ${ }^{6,7)}$. This proposal is supported by the data presented in this study. Octapeptin inhibited formation of the membrane potential generated in the presence of either succinate or Asc/PMS. The antibiotic also inhibited leucine transport which is clearly coupled to the bacterial membrane potential.

The molecular mechanism underlying octapeptin's effects on membrane permeability is not establishec. However, the peptide probably does not function as a proton ionophore since it bears a net positive charge of four at physiological $\mathrm{pH}$ and relatively high densities of bound antibiotic were required to inhibit bacterial growth and formation of the membrane potential. Furthermore, previous studies using octapeptin covalently attached to agarose beads illustrated that the antibiotic can affect the permeability and respiration of spheroplasts and protoplasts by interacting with the outside surface of vesicles ${ }^{21}$. It has been proposed that octapeptin interacts electrostatically with membrane lipid phosphates with insertion of the fatty acid tail into the center of the membrane. These interactions may cause disruption of membrane lipid packing and surface charge and lead to increased small ion permeability. This hypothetical model can account for all of the biochemical effects of octapeptin and is most consistent with the available data.

\section{References}

1) Meyeirs, E.; W. E. Brown, P. A. Principe, M. L. Rathnum \& W. L. Parker: EM49, a new peptide antibiotic. I. Fermentation, isolation, and preliminary characterization. J. Antibiotics 26: 444 448, 1973

2) Meyelrs, E.; F. E. Pansy, H. I. Basch, R. J. McRipley, D. S. Slusarchyk, D. S. Graham \& W. H. Trejo: EM49, a new peptide antibiotic. III. Biological characterization in vitro and in vivo. J. Antibiotics 26: $457 \sim 462,1973$

3) Parkir, W. L. \& M. L. Rathnum: EM49, a new peptide antibiotic. II. Chemical characterization. J. Antibiotics 26: 449 456, 1973

Fig. 5. Asc/PMS dependent $\left[{ }^{3} \mathrm{H}\right]$-leucine uptake by E. coli membrane vesicles in the presence of CCCP. Conditions identical to Fig. 2. Experimental conditions are identical to those indicated in Fig. 1.

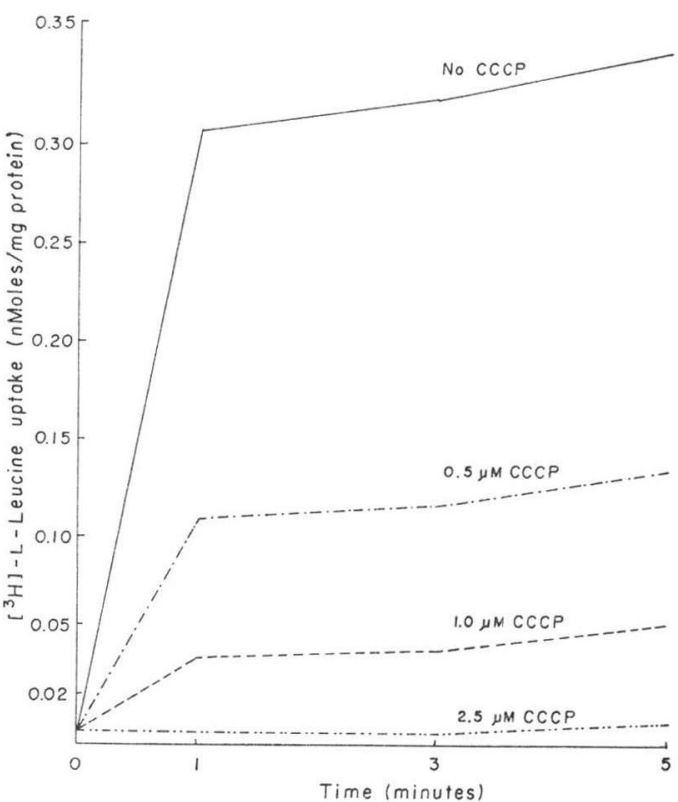


4) Parker, W. L. \& M. L. Rathnum: EM49, a new peptide antibiotic. IV. The structure of EM49. J. Antibiotics 28: 379 389, 1975

5) Meyers, E.; W. L. Parker, W. E. Brown, J. Shoji \& Y. Wakisaka: A nomenclature proposal for the octapeptin antibiotics. J. Antibiotics 29: 1241 1242, 1976

6) Storm, D. R.; K. S. Rosenthal \& P. E. Swanson: Polymyxin and related peptide antibiotics. Ann. Rev. Biochem. 46: 723 763, 1977

7) Rosenthal, K. S.; R. A. Ferguson \& D. R. Storm: Mechanism of action of EM49, membrane-active peptide antibiotics. Antimicr. Agents \& Chemoth. 12: 665 672, 1977

8) Davis, B. D. \& E. S. Mrngioli: Mutants of Escherichia coli requiring methionine or vitamin $\mathrm{B}_{12}$. J. Bacteriol. 60: 17 28, 1950

9) KABACK, H. R.: Bacterial membranes. Methods Enzymol. 22: 99 120, 1971

10) KabACK, H. R.: Transport in isolated bacterial membrane vesicles. Methods Enzymol. 31: 698 709, 1974

11) Rosenthal, K. S.; P. E. Swanson \& D. R. Storm: Disruption of Escherichia coli outer membranes by EM49. A new membrane active peptide antibiotic. Biochemistry 15: 5783 5792, 1976

12) KABACK, H. R. \& E. M. BARnES, Jr.: Mechanisms of active transport in isolated membrane vesicles. II. The mechanism of energy coupling between D-lactic dehydrogenase and $\beta$-galactoside transport in membrane vesicle preparations from Escherichia coli. J. Biol. Chem. 246: 5523 5531, 1971

13) Lowry, O. H.; N. J. Rosebrough, A. L. Farr \& R. J. Randall: Protein measurement with the Folin phenol reagent. J. Biol. Chem. 193: 265 275, 1951

14) Schuldiner, S. \& H. R. KabACK: Membrane potential and active transport in membrane vesicles from Escherichia coli. Biochemistry 14: 5451 5456, 1975

15) Altendorf, K.; H. Hirata \& F. M. Harold: Accumulation of lipid-soluble ions and of rubidium as indicators of the electrical potential in membrane vesicles of Escherichia coli. J. Biol. Chem. 250: 1405 1412, 1975

16) Ramos, S. \& H. R. KABACK: The electrochemical proton gradient in Escherichia coli membrane vesicles. Biochemistry 16: $848 \sim 854,1977$

17) Ramos, S.; S. Schuldiner \& H. R. KABACK: The electrochemical gradient of protons and its relationship to active transport in Escherichia coli membrane vesicles. Proc. Natl. Acad. Sci., U.S.A. 73: 1892 1896, 1976

18) Lombardi, F. J.; J. P. Reeves \& H. R. Kaback: Mechanisms of active transport in isolated bacterial membrane vesicles. XIII. Valinomycin-induced rubidium transport. J. Biol. Chem. 248: 3551 3565, 1973

19) Konings, W. N.; E. M. Barnes, Jr. \& H. R. Kaback: Mechanisms of active transport in isolated membrane vesicles. III. The coupling of reduced phenazine methosulfate to the concentrative uptake of $\beta$-galactosides and amino acids. J. Biol. Chem. 246: 5857 5861, 1971

20) Hirata, H.; K. Altendorf \& F. M. Harold: Role of an electrical potential in the coupling of metabolic energy to active transport by membrane vesicles of Escerichia coli. Proc. Natl. Acad. Sci. U.S.A. 70: $1804 \sim 1808,1973$

21) LaPorte, D. C.; K. S. Rosenthal \& D. R. Storm: Inhibition of Escherichia coli growth and respiration by polymyxin B covalently attached to agarose beads. Biochemistry 16: 1642 1648, 1977 